\title{
A Comparative Review of Material Properties for Current and Future Dental Filling Nanomaterials
}

\author{
Joshua A. Eisenstat, Dennis A. Gotthardt, Rebecca Assor, Liam R. Dempsey and Muhammad H. \\ Hasan
}

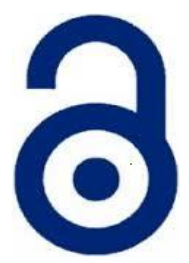

Received: 10 February 2021

Accepted: 20 April 2021

Published: 01 October 2021

Publisher: Deer Hill Publications

(C) 2021 The Author(s)

Creative Commons: CC BY 4.0

\begin{abstract}
Nanomaterials observe specialized properties relative to gross materials. Due to their small size, specialized nanomaterial properties include decreased reactivity, an increased surface area to volume ratio, heightened structural properties, and in some cases, antimicrobial and antibacterial effects. Current researchers are looking to use nanoparticle/nanomaterial properties to solve prevalent dental issues that cannot be addressed with traditionally used materials. This paper serves as an extensive review of current nanomaterial applications as they pertain to dental fillings and dental filling processes. Comparative assessments of traditional materials used in dental fillings were made, as well as comparative assessments of currently used nanomaterials in dental fillings. Material comparisons are based on criteria pertaining to biocompatibility, toxicity, reactivity, cost, and antimicrobial/antibacterial properties. When comparing the three most currently used dental filling nanomaterials - Carbon-Based Nanotubes, Silica Nanoparticles and Silver-Coated Nanoparticles - it was observed that Silica Nanoparticles demonstrated the greatest material advantage and should be recommended for continued use. Issues regarding future developmental dental filling applications of graphene nanoparticles, starch nanoparticles, organic nanoparticles and gold nanoparticles were also reviewed.
\end{abstract}

Keywords: Nanomaterials, antibacterial, dental fillings, silica resins, biocompatibility.

\section{INTRODUCTION}

Strong emphasis is placed on oral hygiene and dental appearance in western society. This is evident when observing the financial capital designated towards dental care in western countries. In 2015, Canada spent 12.7 billion dollars on dental care [1]. Comparatively, the United States of America spent 124 billion dollars on dental care [2].

The current spectrum of dental procedures ranges from physical repairs - dental fillings, root canals - to cosmetic procedures, such as teeth whitening. The World Health Organization reported that roughly 60-90 percent of children and about 100 percent of adults worldwide have experienced cavities [3]. As a result, dental fillings are the most performed dental procedures [4]. Traditional dental filling materials include amalgam, glass ionomers, resin ionomers, resin composites as well as gold and nickel alloys [5]. Among traditional dental filling materials, each observes distinct advantages and disadvantages. Since some materials have better properties than others - life expectancy, toxicity, corrosion, etc.- it is often difficult to find the optimal dental filling material [5]. Faced with complications associated with traditional dental filling materials, researchers are looking to nanomaterials for solutions.

Nanomaterials are composed of nanometer sized particles. Due to the small particle size, nanomaterials often exhibit special physical and chemical properties not observed in gross materials [5]. Due to the special properties of nanomaterials, extensive research has been conducted looking into the advantages and disadvantages of using nanomaterials for medical and dental applications [6]. This paper will provide a comprehensive review of the current methods for using nanomaterials in dental fillings, an in-depth comparison of those current methods - highlighting advantages and disadvantages, as well as look into future developments regarding the applications of nanomaterials in dental fillings.

\author{
Eisenstat, J. A. ${ }^{1}$, Gotthardt, D. A. ${ }^{1}$, Assor, R. ${ }^{1}$, Dempsey L. R. ${ }^{1}$ and Hasan, M. H. ${ }^{2}$ 凶 \\ 'Department of Electrical, Computer, and Biomedical Engineering \\ ${ }^{2}$ Department of Mechanical and Industrial Engineering \\ Ryerson University, Canada \\ E-mail: hasibulhasan@ryerson.ca
}

Reference: Eisenstat et al. (2021). A Comparative Review of Material Properties for Current and Future Dental Filling Nanomaterials. International Journal of Engineering Materials and Manufacture, 6(4), 225-241. 


\section{TRADITIONAL DENTAL FILLINGS - AN OVERVIEW}

A variety of traditional materials are used for dental filling procedures. Traditionally used dental filling materials include dental amalgams, resin ionomers, composite resins and glass ionomers. Dental filling material selection is based on properties including viscosity, moldability and the ideal marginal integrity of the dental filling in the tooth [7]. Dental fillings are also chosen based on susceptibility to corrosion from $\mathrm{pH}$, temperature, protein, saliva, oral health conditions, and diet [8]. Saliva, for example, has a pH range of 5.2 to 7.8. Food consumption and diet must also be taken into consideration during dental filling material selection. The more acidic the food is, the more likely corrosion will occur to dental fillings and teeth [8]. Among traditionally used dental filling materials, there is not one material that provides a solution to all problems. In fact, some currently used traditional dental filling materials can induce unintended health defects. For example, dental amalgam - a commonly used dental filling material - could pose health risks for patients due to its high mercury concentration [5]. Traditional dental filling materials each come with their respective advantages and disadvantages [5].

Table 1: Advantages and Disadvantages of Traditional Dental Fillings [5]

\begin{tabular}{|c|c|c|}
\hline Dental Filling & Advantages & Disadvantages \\
\hline Dental Amalgam & $\begin{array}{ll}\text { - } & \text { Durable } \\
\text { - } & \text { Inexpensive } \\
\text { - } & \text { Good Corrosion Resistance }\end{array}$ & $\begin{array}{l}\text { - } \quad \text { Aesthetically displeasing } \\
\text { - Potential Toxic Mercury } \\
\text { Content }\end{array}$ \\
\hline Resin lonomer & $\begin{array}{ll}\text { - } & \text { Aesthetically pleasing } \\
\text { - } \quad \text { Limited Sensitivity to Temperature } \\
\text { Changes } \\
\text { - } \quad \text { Relatively Good Against Future Decay }\end{array}$ & $\begin{array}{l}\text { - Poor Wear Resistance } \\
\text { - } \quad \text { Expensive }\end{array}$ \\
\hline $\begin{array}{l}\text { Composite } \\
\text { Resins }\end{array}$ & $\begin{array}{ll}\text { - } & \text { Good Strength and Toughness } \\
\text { - } & \text { Aesthetically Pleasing } \\
\text { - } & \text { Good Wear Resistance }\end{array}$ & $\begin{array}{l}\text { - } \quad \text { Varying tooth sensitivity } \\
\text { Sensitive to temperature } \\
\text { changes } \\
\text { - Expensive }\end{array}$ \\
\hline Glass lonomers & $\begin{array}{ll}\text { - } & \text { Aesthetically Pleasing } \\
\text { - } & \text { Relatively Good Against Future Decay } \\
\text { - } & \text { Minimal Sensitivity }\end{array}$ & - $\quad$ Poor Wear Resistance \\
\hline
\end{tabular}

\subsection{Nanomaterial Dental Filling Biocompatibility}

External materials can be inserted into the body only if they are biocompatible with live tissue. Nanomaterials are said to be biocompatible if a homogeneous composition can be made with the inserted nanomaterial and biological tissue. Homogeneous nanomaterials demonstrate satisfactory biocompatibility in the patient's oral cavity relative to heterogeneous nanomaterial compositions [9]. If the added nanomaterials observe high levels of reactivity with the inorganic dental filling material, it is an indication of a homogeneous composition. High levels of nanoparticle reactivity with dental fillings are observed to be beneficial [9]. However, if the added nanomaterials have a high level of reactivity with soft tissue in the oral cavity - gums, enamel, tongue - then the biocompatibility of the dental filling is deemed unsatisfactory, and the nanoparticle's high level of reactivity becomes problematic [9]. Material reactivity is determined by quantifying the relationship of the surface area relative to the given volume ratio of the particles [10]. This relationship can be described using the following equations 1-3 [10]. As the radius of a particle decreases, reactivity of the particle increases, as illustrated in the mathematical principles in equation 3 . Due to the small radius of nanoparticles, chemical reactivity increases gradually. Nanomaterial toxicity is a result of their small particle size. Smaller particle size allows for easier passage through different body membranes [11].

$$
\begin{aligned}
& \text { Surface Area }=4 \pi r^{2} \\
& \qquad \text { Volume }=\frac{4}{3} \pi r^{3} \\
& \text { Reactivity }=\frac{\text { Surface Area }}{\text { Volume }}=\frac{4 \pi r^{2}}{\frac{4}{3} \pi r^{3}}=\frac{3}{r}
\end{aligned}
$$




\section{CURRENT AND PREVIOUSLY CONDUCTED DENTAL FILLING NANOMATERIAL RESEARCH 3.1 Polymethyl Methacrylate (PMMA)}

The most common material used in dental fillings today are composite resin fillings [12]. This is due to the visual similarity of the resin material and dental tissue. Current research has developed a nanomaterial composite resin filler as an alternative to traditionally used composite resin fillers. Polymethyl methacrylate (PMMA) is a nanocomposite resin filling that has been observed to be a more effective resin filler than current composite resin filler variants. Experimental trials determined that a $5 \%$ volume fraction of $40 \%$ Titania $\left(\mathrm{TiO}_{2}\right)$, and $60 \%$ Calcium Aluminate $\left(\mathrm{CaAl}_{2} \mathrm{O}_{4}\right)$ nanoparticles presented the longest life, best surface interactions (tribological characteristics), and the most stable nano-composition supported by nanoparticles [12]. Under experimental trials, PMMA has exhibited satisfactory cytotoxicity metrics by demonstrating low damage to erythrocytes and even promoting cellular activity [13]. Additionally, PMMA has seen expanded use cases regarding denture efficacy and applicability. When compared to other artificial materials PMMA has demonstrated a harder enamel surface replacement and increased wear resistance [14].

\subsection{Nanomaterial Composite Resins}

Research has been done to create new nanoparticle composite resins [15]. Composite resins are a type of restorative material [15]. Examples being strengthening agents like mineral filler particles [15]. These materials can be dispersion reinforced, particulate reinforced, or hybrid composites. Although these resins have high dispersion reinforcement, microfill resins are relatively weak structurally. This limits them only to low stress restorations [15]. The goal of this dental filling material was to retain high strength properties for load-bearing restorations and keep its glossy appearance after long periods of wear [15].

The dental composite is applied to the teeth and then exposed to a light source. The light source is used to cure the resin material. The resin is suitable for use in stress bearing applications because of its flexural strength of more than $100 \mathrm{MPa}$ [15]. Structural fillers that are suitable for this resin are barium magnesium aluminosilicate glass, barium aluminoborosilicate glass (BAG), amorphous silica, silica-zirconia, silica-titania, barium oxide, quartz, alumina and various other inorganic oxide particles [15]. The particles present have an average particle size of $0.05 \mu \mathrm{m}$ to 0.50 $\mu \mathrm{m}$ plus a nanofiller, which observes an average particle size of roughly $100 \mathrm{~nm}$ [15].

\subsection{Silica Nanomaterial Resins}

Silica nanoparticles are featured prominently in various current dental filling applications. Largely due to the high wear resistance and strong antimicrobial and antibacterial properties [16]. Studies have demonstrated significant reduction in oral bacteria Escherichia. Coli and Staphylococcus aureus when placed near silica nanoparticles, highlighting antibacterial effectiveness against both gram-negative and gram-positive bacteria [17].

A common use case of silica nanoparticles is the infusion of silica nanoparticles within traditional dental filling materials. In one study, silica nanoparticles (OX-50) and porous diatomite particles were combined with resin to further determine their combined mechanical properties [18]. Silica and porous diatomite particles were added to dental resin at different mass ratios ranging from $60 \%-75 \%$ [18]. It was observed that with the increase of the silica - diatomite mass composition, the mechanical properties of the resin increased. With the highest microhardness composite at $75 \%$ of silica - porous diatomite particles, it was determined that nanosized silica and porous diatomite particles have a demonstrable impact on the mechanical properties of dental resin composites [18].

\subsection{Silver Coated Nanomaterials}

Optical glass fibers can be coated with silver nanoparticles. This was an alternative material for root dental fillings during endodontic therapy (root canal treatment) [19]. The material was used because of its mechanical and antibacterial properties [19]. A group of glass fiber filaments were covered with silver nanoparticles and then placed in a solvent of tetrahydrofuran [19]. Synthesis of the silver nanoparticles involved combining silver nitrate $\left(\mathrm{AgNO}_{3}\right)$ and sodium borohydride $\left(\mathrm{NaBH}_{4}\right)$ at a 3:1 ratio. Sodium borohydride acts as a reducing agent for silver nitrate [19]. After 24 hours of stirring and centrifuging, the nanoparticles were dried at room temperature and recovered. Mechanical properties of hardness and elastic modulus were evaluated on the surface of optical glass coated with the silver nanoparticles. Using the process of nanoindentation, the hardness value of $3.6 \pm 0.17 \mathrm{GPa}$ and an elastic modulus of $78.3 \pm 2.6 \mathrm{GPa}$ were determined [19]. The results can be seen in Figure 1 .

\subsection{Metallic Nanomaterials}

The introduction of tin, copper, mercury, and silver nano powders and composite nano powders, synthesized using Salvia miltiorrhiza Bunge root extract, play a large role in dental filling antibacterial properties [20]. Salvia miltiorrhiza acts as a reducing and capping agent to improve the antibacterial property of dental fillings [20]. Metallic nanoparticle properties include small particle size, high surface area to volume ratio, stability, high dispersity, non-cytotoxicity, and biocompatibility that make them beneficial for dental fillings [20]. New and evolving pathogens must be considered when developing dental fillings. Failures in restorative dentistry are mostly attributed to the presence of oral bacteria [20]. The copper composite nano powder, Salvia miltiorrhiza root extract, and silver nano powder demonstrated strong antibacterial properties against the oral bacteria Streptococcus mutans and Lactobacillus acidophilus [20]. These two strains of bacteria are some of the most prevalent forms of bacteria in the oral cavity 
and are the main causes for dental caries [20]. The application of metal nano powders as alternatives for antibiotics and disinfectants in dental filling materials show promising experimental results [20].
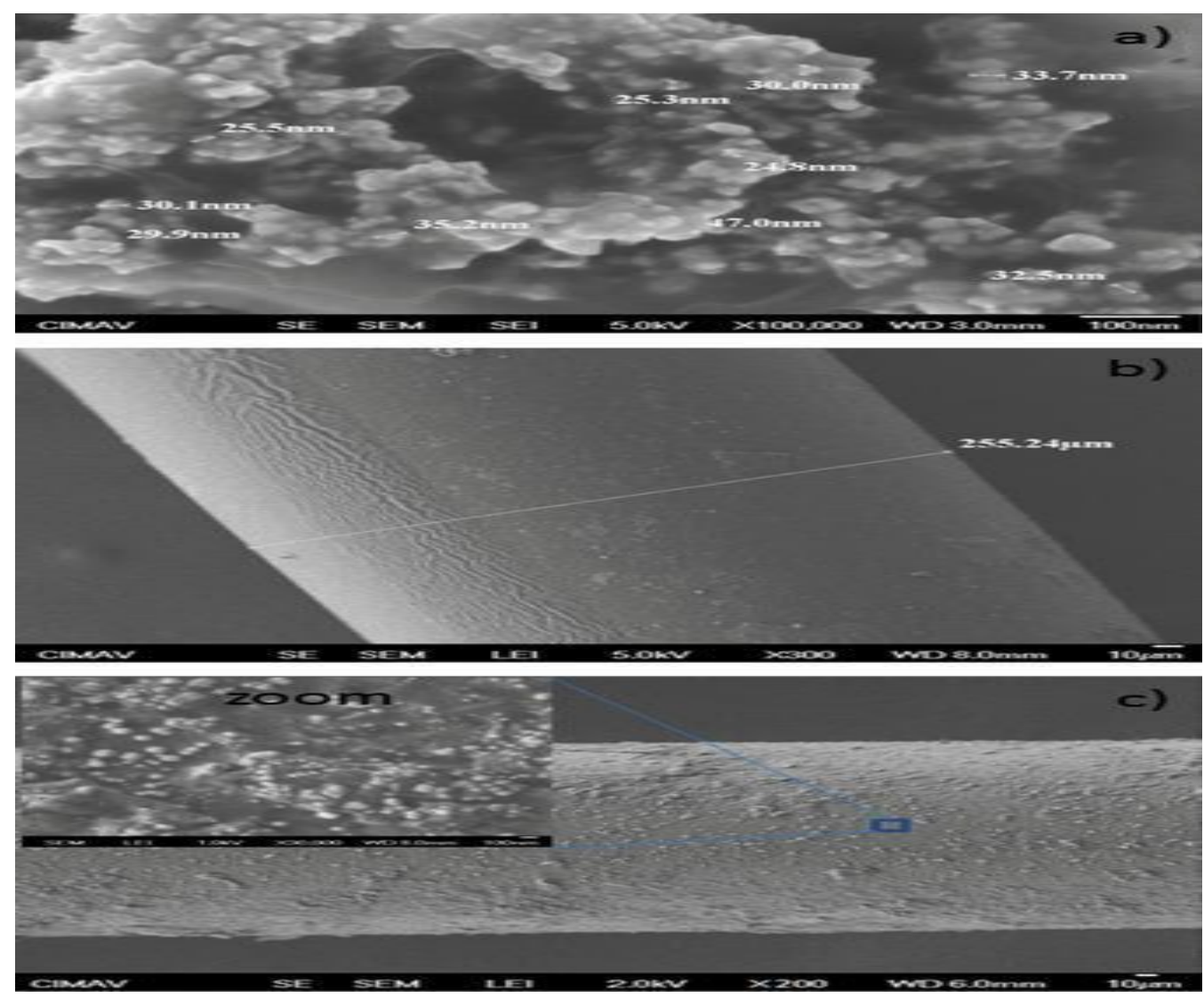

Figure 1: SEM micrographs: (a) synthesized silver nanoparticles by chemical reduction, (b) the optic fiber without silver nanoparticles coated on the surface of glass fiber cores, (c) the optic fiber with silver nanoparticles coated on the surface of glass fiber cores [19]

\subsection{Dental Cement}

Root canals are a common surgery in dentistry. Surveys conducted by the American Association of Endodontists observed that 15.1 million root canal procedures were conducted in 2005 and 2006 respectively [3]. Root canals involve the cleaning and removal of an infected tooth nerve followed by the placing of the filling material such as Gutta-Percha in the canal space. As the infected nerve is removed the subsequent nerve space is filled with dental material to prevent infection. The most common type of filling used for root canal procedures is Gutta-Percha, a natural resin and thermoplastic elastomer [21,22]. Gutta-Percha is seen in three different forms. $-\alpha$, $\beta$, or $\gamma$. The form of Gutta-Percha is dependent on the rate of material cooling. If Gutta-Percha is cooled at less than half a degree Celsius per hour, then $\alpha$-Gutta-Percha is formed [23]. Gutta-Percha observes biological inertness, reversibility and non-conductibility [23].

Despite many beneficial properties, there are concerns regarding the ability of Gutta-Percha's material to properly secure the root canal [21]. As a result of this, many sealants have been introduced to work with the filling material. However, the non-polar nature of most sealants renders them incompatible with the polar regions of the oral cavity [21]. 
To overcome these drawbacks, new patents for dental cement compositions have been created. Dental cement is comprised of various nanoparticles; Di-calcium Silicate $\left(\mathrm{Ca}_{2} \mathrm{SiO}_{4}\right)$, Tricalcium Silicate $\left(\mathrm{Ca}_{3} \mathrm{SiO}_{5}\right)$, Bismuth Oxide $\left(\mathrm{Bi}_{2} \mathrm{O}_{3}\right)$, Gypsum, Strontium Carbonate $\left(\mathrm{SrCO}_{3}\right)$, Zeolite, Calcium Sulfate $\left(\mathrm{CaSO}_{4}\right)$ Di-sodium Hydrogen Phosphate $\left(\mathrm{Na}_{2} \mathrm{HPO}_{4}\right)$ and Tricalcium Aluminate $\left(\mathrm{Ca}_{3} \mathrm{Al}_{2} \mathrm{O}_{6}\right)$ [21]. Dental cement is used as root-end filling material and demonstrates a fast-setting time, despite saliva and blood exposure. Dental cement also hardens at temperatures corresponding to bodily ideals at 36.1 to 37.2 degrees Celsius [21]. An important feature of dental cement are its microhardness and strength which come as a result of the nanoparticles in chemical solution [21]. For example, the gypsum incorporated into the solution has a chemical formula of $\mathrm{CaSO}_{4} \bullet 2 \mathrm{H}_{2} \mathrm{O}$ [24]. The calcium sulfate is primarily known as anhydrite; however, the addition of water molds the material into that of nano-gypsum, which demonstrates significantly higher than normal levels of microhardness [25]. Ostewalder et al. conducted an experiment in which the microhardness of nano-gypsum was compared to an alabaster reference which has a similar chemical formula $\mathrm{CaSO}_{4} \bullet 0.25 \mathrm{H}_{2} \mathrm{O}$ to that of nano-gypsum at varying powder to water ratios [25]. Their findings demonstrated that regardless of the water to powder ratio, the nano-gypsum demonstrated a compelling increase in Vickers Hardness $\left(\mathrm{kg} / \mathrm{mm}^{2}\right)$, up to approximately 3.18 times as hard as its Alabaster reference at a water to powder ratio of 0.22 [25].

\subsection{Gutta Percha with Nano-diamonds}

Nano-diamonds, a type of carbon-based nanoparticles, have been found to have great antibacterial effects against both Gram-positive and Gram-negative bacteria, as well as S. aureus, E. coli and S. mutans - typical bacteria found in the oral cavity [26]. Moreover, the addition of nano-diamonds into resin-based materials had improved their antibacterial and properties. The use of Gutta-Percha was explained previously, however, there is a new and improved form of Gutta-Percha with nano-diamonds incorporated into the product that is currently undergoing trials by the American government [26]. With this invention, root canal fillers will be more stable, stronger and protect against harmful bacteria more efficiently with the hopes of preventing secondary caries [27].

\section{CURRENT NANOMATERIAL DENTAL FILLINCS - A COMPARISON}

Based on current research, the three most currently used nanomaterials in dental fillings - carbon nanotubules, silver nanoparticles and silica nanoparticles - were assessed in order to determine which application is most optimal. Each method of nanomaterial utilization observed their own respective advantages and disadvantages [4].

Due to their covalent and hexagonal bonding structures, carbon nanotubules present strong mechanical properties. This includes high strength, low particle densities and heat stability [5]. Carbon nanotubules observe strong adhesive properties when applied to cementum and dentin surfaces. Unfortunately, carbon nanotubules' applications in dental fillings have demonstrated cases of adverse biological reactions. Reactions have included inflammation of the dental filling areas due to small carbon nanotubule particles crossing over membranes [5]. Carbon Nanotubes have been shown to demonstrate promising outcomes when combined with composite resins. Evidence suggests current composite resins present problems regarding resistance to future caries in dental fillings. This means that in composite resin fillings there exists a high possibility for gaps to be formed between the filling and the tooth, termed as either outer lesions or wall lesions [28]. Depending on whether the size of the gap is small or large, either a micro-leak or macro-leak will ensue [28]. These gaps and leaks within the tooth filling can then harbor bacteria leading to secondary caries [29]. Due to the antimicrobial properties of carbon nanotubes, their infusion within composite resin materials disrupts bacteria formation within gaps and leaks, generating a preventative effect against tooth decay and development of secondary caries [29].

Silver nanomaterial compounds are used largely due to their antibacterial and antimicrobial properties. While relative toxicity of silver nanomaterials is low compared to other dental filling nanomaterials, overall biological risk is larger due to the severity of potential toxic effects. Silver can alter DNA base pairings; cause DNA unwinding and disrupt cellular phagocytosis and actin function [5]. Silver oxide nanoparticles were experimented with to determine if they possess antimicrobial properties against Streptococcus mutans and Lactobacillus [30]. As mentioned previously, these two strains of bacteria are found in oral cavity, resulting in dental caries [31,32]. It was found that composite resins with either silver or zinc-oxide nanoparticles added into the solution demonstrated greater antibacterial activity against both Streptococcus mutans and Lactobacillus [30].

Silica nanomaterials are an inexpensive nanomaterial dental filling alternative, relative to carbon nanotubules and silver nanomaterials. An advantage of incorporating silica nanomaterials is the improved wear resistance that they provide dental fillings [6]. As a dental filling wears, particles are shed from the surface of the dental filling and the tooth roughens [33]. The size of the particles shed are crucial for the composition of the remaining tooth. Larger particle shedding can lead to poor tooth filling composition. When traditional dental fillers are used, shed tooth particles are larger, and the shedding of the given particles will result in a rougher filling surface [33]. When nanomaterials are introduced to the filling material, particle shedding has a minimal effect on tooth filling composition due to the small particle size. This leads to less apparent tooth roughness, such as when silica nanomaterials are used [33]. However, due to the small size of silica nanomaterials, there are a few potential health risks involved. Silica nanoparticles can cause reactive oxygen species (ROS) and additional oxidative stress. As a reference, there were higher amounts of ROS, lactate dehydrogenase (LDH), and malondialdehyde reported when 
treating non-small cell lung cancers or in other words bronchoalveolar carcinoma, with silica nanoparticles at an exposure rate of $10-100 \mu \mathrm{g} / \mathrm{mL}[34,35]$.

Dental composites that release a disinfectant called chlorhexidine $(\mathrm{CHX})$ have been found to have inferior mechanical properties than composites that do not release $\mathrm{CHX}$ [36]. However, as mentioned previously, preventing secondary caries are significant when applying dental fillings. Therefore, experiments have been conducted to investigate whether the antibacterial $\mathrm{CHX}$ can be present in the filling without jeopardizing the mechanical properties of the filling. $\mathrm{CHX}$ is used across the dental field due to its strong antibacterial activity alongside its low cytotoxicity in the oral cavity [36]. SBA-15 mesoporous silica nanoparticles (MSN) were mixed with CHX and then tested for the ejection of $\mathrm{CHX}$, the flexural strength and modulus, surface roughness and the antibacterial activity against the same bacteria as mentioned previously, Streptococcus mutans and Lactobacillus [36].

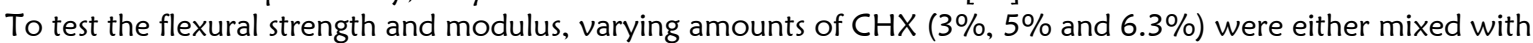
the MSN or not mixed with the MSN and each mixture was then compared to a control set at times of 24- hours and 1 month [36]. Based on the results of the experiment, the flexural strength and modulus of the composites containing mixtures of $\mathrm{CHX}$ with MSN were greater for about every level of $\mathrm{CHX}$ percentage at both twenty-four hours and one month compared to the composites with only $\mathrm{CHX}$. This can be visualized in Figure 2, as the blue and grey bars ( $\mathrm{CHX}$ and MSN) reach higher magnitudes of Flexural Strength in $\mathrm{MPa}$ and Flexural Modulus in GPa, than the pink and green bars (pure $\mathrm{CHX}$ ) [36].
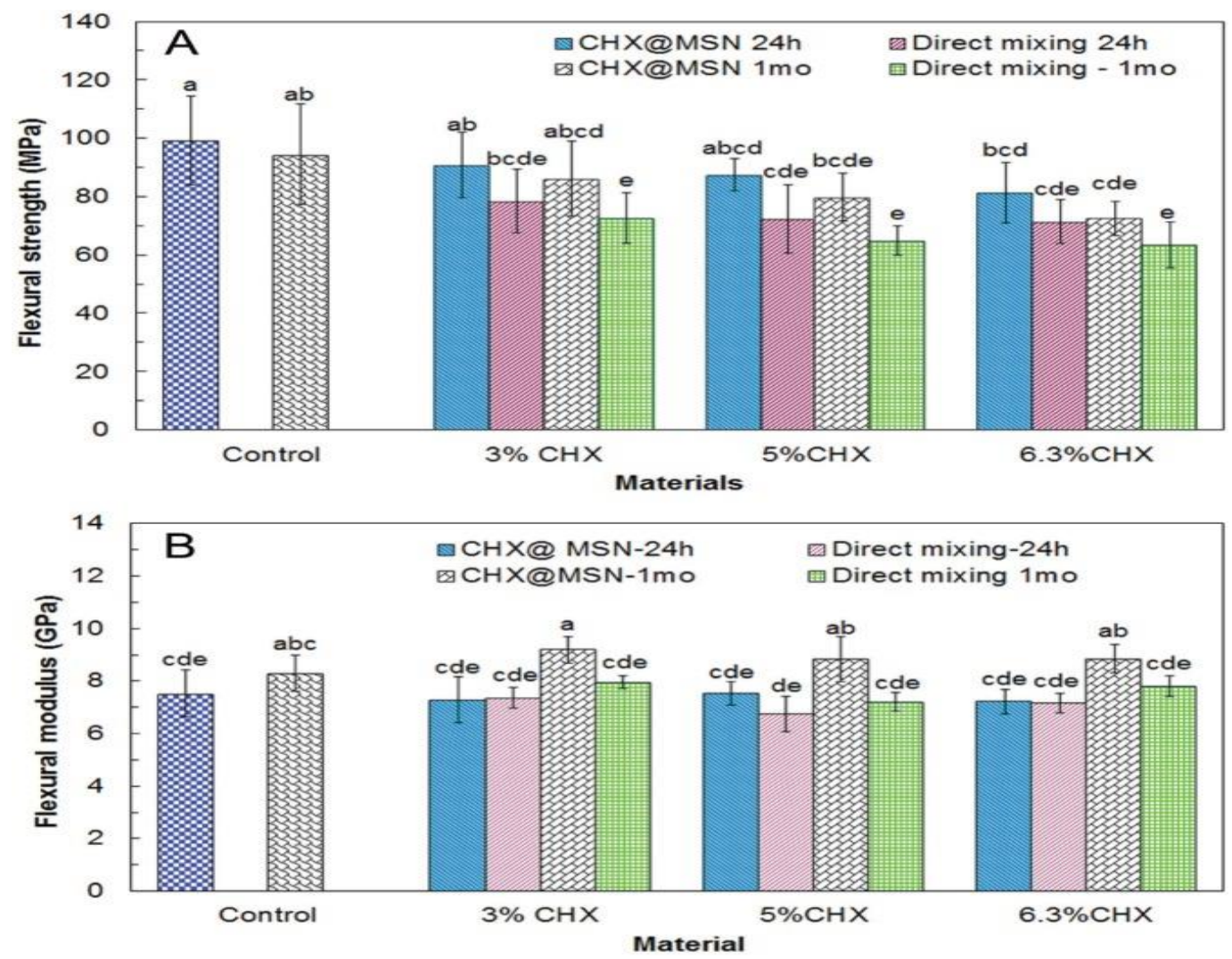

Figure 2: Flexural Strength and Modulus at varying levels of $\mathrm{CHX}$ percentages for pure $\mathrm{CHX}$ and $\mathrm{CHX}-\mathrm{MSN}$ mixture at both 24 hours and 1 month [36]

Regarding the release of $\mathrm{CHX}$ from the composite with respect to time, the composite with the purely $\mathrm{CHX}$ mixture released the $\mathrm{CHX}$ at a much more rapid rate at the start, however, very soon later the rate tapered off [36]. The goal for this composite is to have a continuous release of $\mathrm{CHX}$ to prevent secondary caries. Therefore, the composite composed of $\mathrm{CHX}$ and MSN mixture is preferable despite having a slower release rate of $\mathrm{CHX}$ at the beginning, as it has a more sustainable release of $\mathrm{CHX}$ over time, as seen in Figure 3 [36]. 

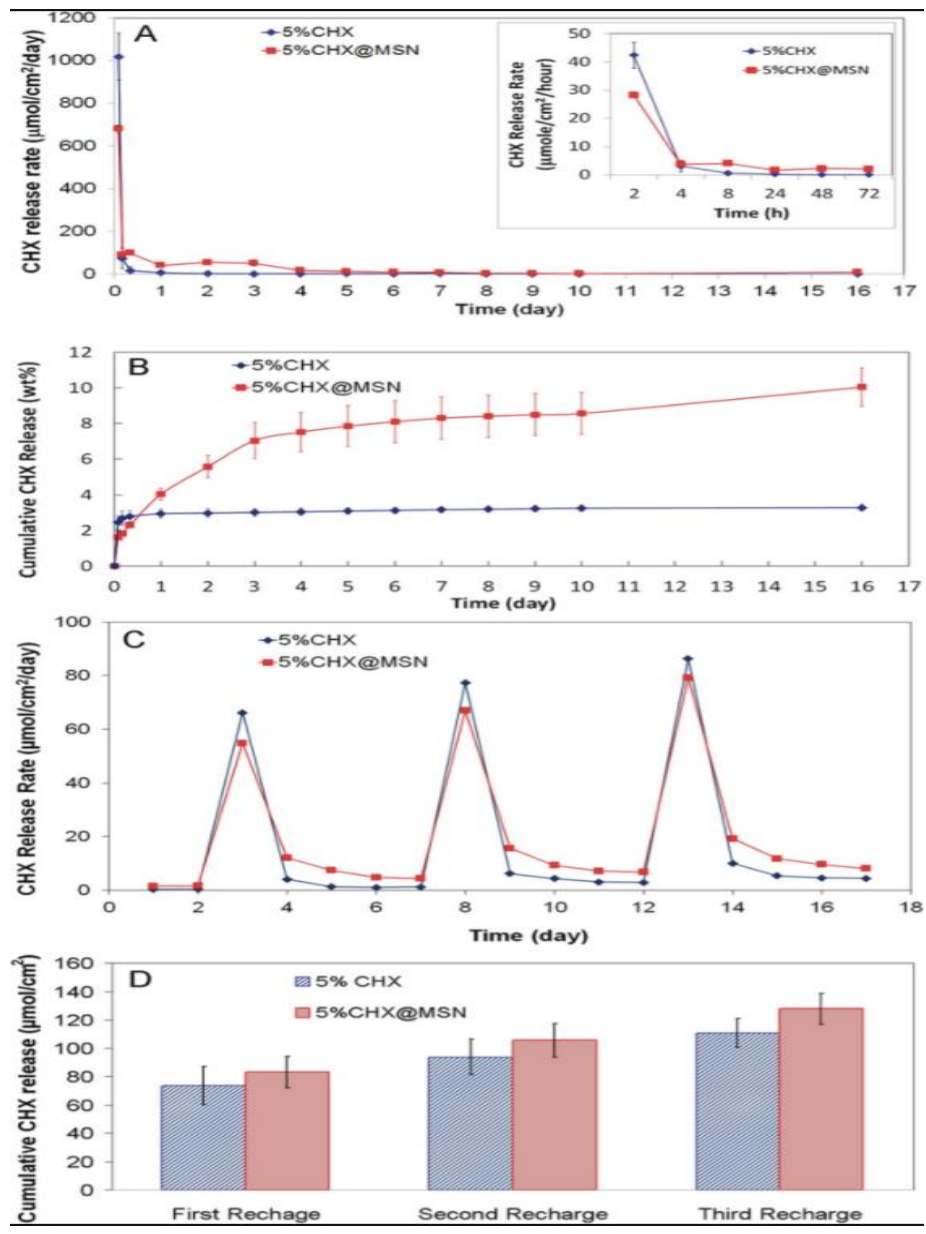

Figure 3: Ejection levels of $\mathrm{CHX}$ with respect to time for pure and $\mathrm{CHX}-\mathrm{MSN}$ mixture [36]

In a different study conducted by Stewart et al. it was found that utilizing MSN allows for improved antimicrobial characteristics [37]. This is yet another study that proves the advantages of incorporating MSN into dental fillings, as they facilitate the release of antimicrobial agents more efficiently, ultimately aiding in the prevention of secondary caries [37]. They developed a dental adhesive, which combines the MSN and an antibacterial drug called octenidine dihydrochloride [37]. Their adhesive demonstrated no biocompatibility issues and performed well against biofilm formation through the controlled release of the octenidine dihydrochloride [37].

To test the surface roughness of the composite, each composite - pure $\mathrm{CHX}$ and $\mathrm{CHX}-\mathrm{MSN}$ mixture, were submerged under water for a two-week period [36]. Upon removal from the water, it was evident that the composite with a mixture of $\mathrm{CHX}$ and MSN had displayed much greater wear resistance, which is of prime importance when working with dental fillings. Surface roughness is detrimental to a dental filling, as it yields greater wear on the filling [36]. The testing was conducted on composites of 5\% $\mathrm{CHX}-\mathrm{MSN}$ mixture and 5\% pure $\mathrm{CHX}$ mixture, and the surface roughness's prior to exposure of water were measured to be 0.344 and 0.311 respectively. However, after the exposure to water the surface roughness for each composite of $5 \% \mathrm{CHX}-\mathrm{MSN}$ mixture and $5 \%$ pure $\mathrm{CHX}$ mixture were measured to be 0.410 and 1.113 respectively [36]. On the surface of the composite with pure $\mathrm{CHX}$, holes reaching further than $5 \mu \mathrm{m}$ were visible, which can be seen in Figure 4 (B). The holes in the 5\% CHX composite can be attributed to the greater surface roughness of 1.113 [36]. To calculate the percentage difference, the following equation is used:

$$
\text { Percentage Difference }=\frac{\mid \text { NewValue-InitialValue } \mid}{\frac{(\text { NewValue+InitialValue })}{2}} \cdot 100 \%
$$




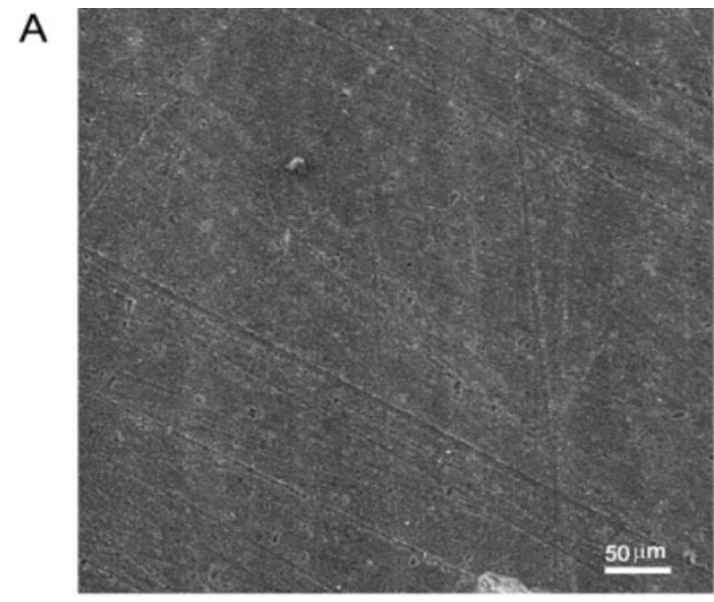

B

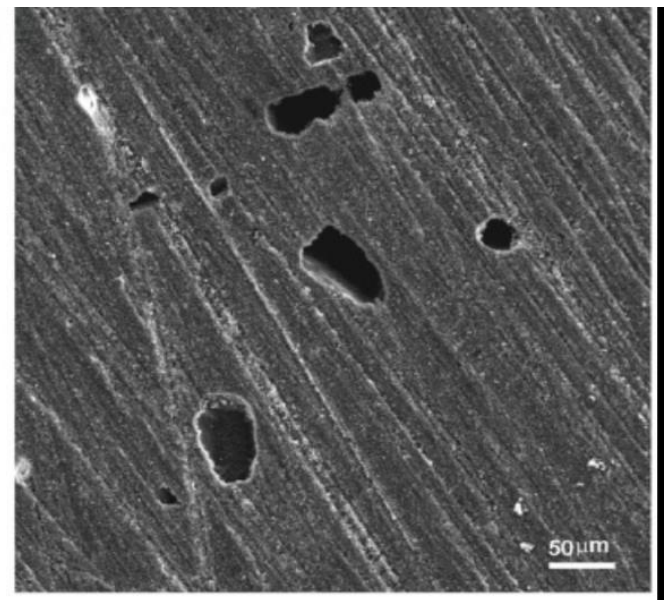

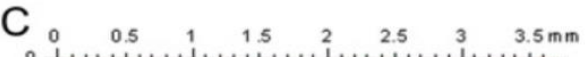

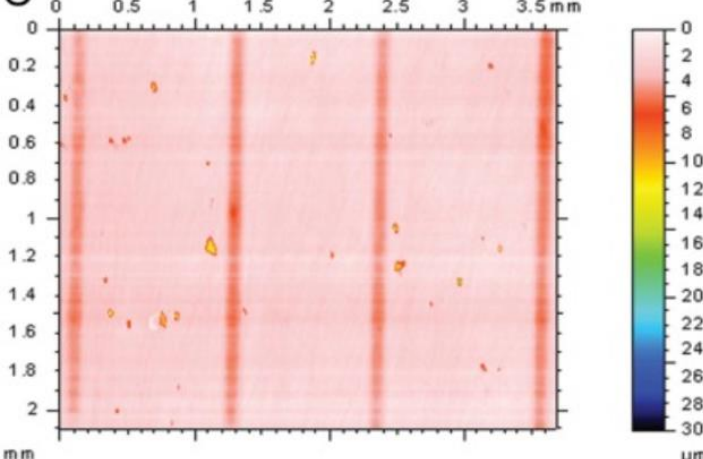

$\mathrm{mm}$

Figure 4: Illustrations of the surfaces of (A) CHX-MSN composite, (B) CHX mixture composite, (C) Surface Roughness graphs for CHX-MSN composite, (D) Surface Roughness graphs for $\mathrm{CHX}$ composite [36]

Through equation 4, better analysis of the change in surface roughness, and thus wear resistance can be made for the different composites of pure $\mathrm{CHX}$ versus that of $\mathrm{CHX}$ and MSN. It is evident from Table 2, that the wear resistance of the composite with the $\mathrm{CHX}$ and MSN mixture is far superior to that of just pure $\mathrm{CHX}$, as the $\mathrm{CHX}$ composite underwent a 112.64 percent increase in surface roughness after being submerged in water for 14 days, compared to the 17.51 percent increase in surface roughness seen by the composite composed of CHX and MSN.

Table 2: Percentage Differences for Surface Roughness of each composite mixture for before and after exposure to water [36]

\begin{tabular}{cccc}
\hline Mixture & $\begin{array}{c}\text { Surface Roughness Before Water } \\
(\mu \mathrm{m})\end{array}$ & $\begin{array}{c}\text { Surface Roughness After Water } \\
(\mu \mathrm{m})\end{array}$ & $\begin{array}{c}\text { Percentage Difference } \\
(\%)\end{array}$ \\
\hline $\mathrm{CHX}$ & 0.311 & 1.113 & 112.64 \\
$\mathrm{CHX}-\mathrm{MSN}$ & 0.344 & 0.410 & 17.51 \\
\hline
\end{tabular}

Experimental trials demonstrate that Silica Nanoparticle infusion increases the physical properties of composite materials [36]. The addition of silica nanoparticles also demonstrated satisfactory antibacterial properties relative to control groups. In the tests conducted by J.F. Zhang et al. there was a significant number of bacteria present in control samples whereas the composite of CHX-MSN mixture had minimal or no bacteria present [36]. These observations can be attributed to the sustainable and more constant release of $\mathrm{CHX}$ from the composite with the CHX-MSN mixture. As a result of this sustainable release of antibacterial $\mathrm{CHX}$, there is less time for the bacteria to accumulate on the surface of the filling. There is a need for consistent exposure to antibacterial substances [36]. J.F, Zhang et al. demonstrated that a consistent $\mathrm{CHX}$ release rate of 0.25 to $1.0 \mu \mathrm{g} / \mathrm{mL}$ for the composite consisting of the CHX-MSN mixture, will drastically lower the risk of bacteria growth and hibernation, and thus lowering the probability of secondary caries [36]. 
Based on the findings of current available research, each type of nanoparticle presents various advantages, and all pose similar disadvantages associated with the health risks and toxicity of the nanoparticles. However, amongst the three most used nanomaterial dental fillings - carbon nanotubules, silver nanomaterials and silica nanomaterials - silica nanomaterials under controlled doses demonstrate the greatest material advantages. Silica nanomaterials improve wear resistance, improve physical and mechanical properties, reduce dental filling tooth roughness, improve the antibacterial properties, and are drastically less expensive relative to silver nanomaterials and carbon nanotubules alternatives $[5,36]$. Although there are health risks associated with silica nanomaterials, the same health risks are also present in carbon nanotubules and silver nanomaterials at greater frequency. Under controlled concentrations, silica nanomaterials produce minimal adverse effects [5].

Table 3: Advantages and Disadvantages of Currently Used Nanomaterial Dental Fillings [5,36]

\begin{tabular}{|c|c|c|}
\hline Nanomaterial Type & Advantages & Disadvantages \\
\hline Carbon Nanotubules & $\begin{array}{ll}\text { - } & \text { Increased Surface Area for } \\
\text { Reactivity } \\
\text { - } \quad \text { Molds well with tooth } \\
\text { - Antimicrobial and Antibacterial } \\
\text { Properties }\end{array}$ & $\begin{array}{l}\text { - Potential Health Risks due to } \\
\text { Small Particle Size. } \\
\text { - } \quad \text { Potential Toxic effects }\end{array}$ \\
\hline Silver & $\begin{array}{ll}\text { - } & \text { Antimicrobial and Antibacterial } \\
\text { Properties } \\
\text { - } \quad \text { Relatively Low Toxicity }\end{array}$ & $\begin{array}{l}\text { - Potential Health Risks due to } \\
\text { Small Particle Size } \\
\text { - } \quad \text { Potential Toxic Effects }\end{array}$ \\
\hline Silica & $\begin{array}{ll}\text { - } & \text { Inexpensive } \\
\text { - } & \text { Improved Wear Resistance } \\
\text { - } & \text { Antimicrobial and Antibacterial } \\
& \text { Properties } \\
\text { - } & \text { Improved Physical and } \\
& \text { Mechanical properties } \\
\text { - } & \text { Absorption Capacity } \\
\text { - } & \text { Reduces Tooth Roughness } \\
\end{array}$ & $\begin{array}{l}\text { Potential Health Risks due to } \\
\text { Small Particle Size }\end{array}$ \\
\hline
\end{tabular}

\section{FUTURE DEVELOPMENTS OF NANOMATERIAL DENTAL FILLING APPLICATIONS 5.1 Graphene Family Nanomaterials}

Graphene Family Nanomaterials (GFN) are potential alternatives to current nanomaterials used in dentistry. GFNs are comprised of many subclasses of graphene nanomaterials including graphene oxide (GO), reduced graphene oxide ( $\mathrm{rGO}$ ), graphene nanosheets (GNS), ultra-thin graphite and few layers graphene (FLG) respectively [39]. Differences between graphene types are attributed to variances in size, layer depth and surface properties as seen in Figure 5 [39].

Much testing has been done regarding the biocompatibility of GFN. GFN tests have been performed in vivo and in vitro with results observing safe and potentially harmful thresholds of GFN concentration in the body. For graphene oxide, $50 \mu \mathrm{g} / \mathrm{mL}$ was determined to be the hypothetical toxicity threshold [37]. At concentrations over 50 $\mu \mathrm{g} / \mathrm{mL}$, graphene oxide may carry damage to T-Cells and fibroblasts [39]. More research still needs to be concluded regarding GFN biocompatibility as no one determinant for toxicity - size, oxidation, iron content, etc. - has been established.

The main area of interest regarding the medical and dental uses of GFN are their antibacterial properties. Relative to other materials currently being used in prosthodontic procedures, Graphene Family Nanomaterials - specifically graphene oxide - have shown to induce the complete elimination of microbial integrity. When tested against three bacteria commonly found in the oral cavity, Streptococcus mutans, Porphyromonas gingivalis, and Fusobacterium nucleatum, graphene oxide nanosheets at a concentration of $40 \mu \mathrm{g} / \mathrm{mL}$ were observed to be highly effective at inhibiting bacterial growth. Antibacterial properties of GFN are however dependent on concentration. By increasing graphene oxide concentration to $80 \mu \mathrm{g} / \mathrm{mL}$, complete eradication of all Streptococcus mutans cultures was observed [39]. For reference, Streptococcus mutans is one the bacteria responsible for dental caries as previously mentioned, Porphyromonas gingivalis is a bacterium responsible for periodontitis, and Fusobacterium nucleatum is a bacterium responsible for root canal infection [39].

In terms of actual application as dental filling agents, GFN are being tested in combination with glass ionomers. Glass ionomers are structurally weak relative to other current filling materials. GFNs are looked at to reinforce glass ionomer structural properties and improve material strength [39]. Additionally, due to the antibacterial properties of GFN, research is being done in order to derive new dental adhesives to be used for filling processes. 


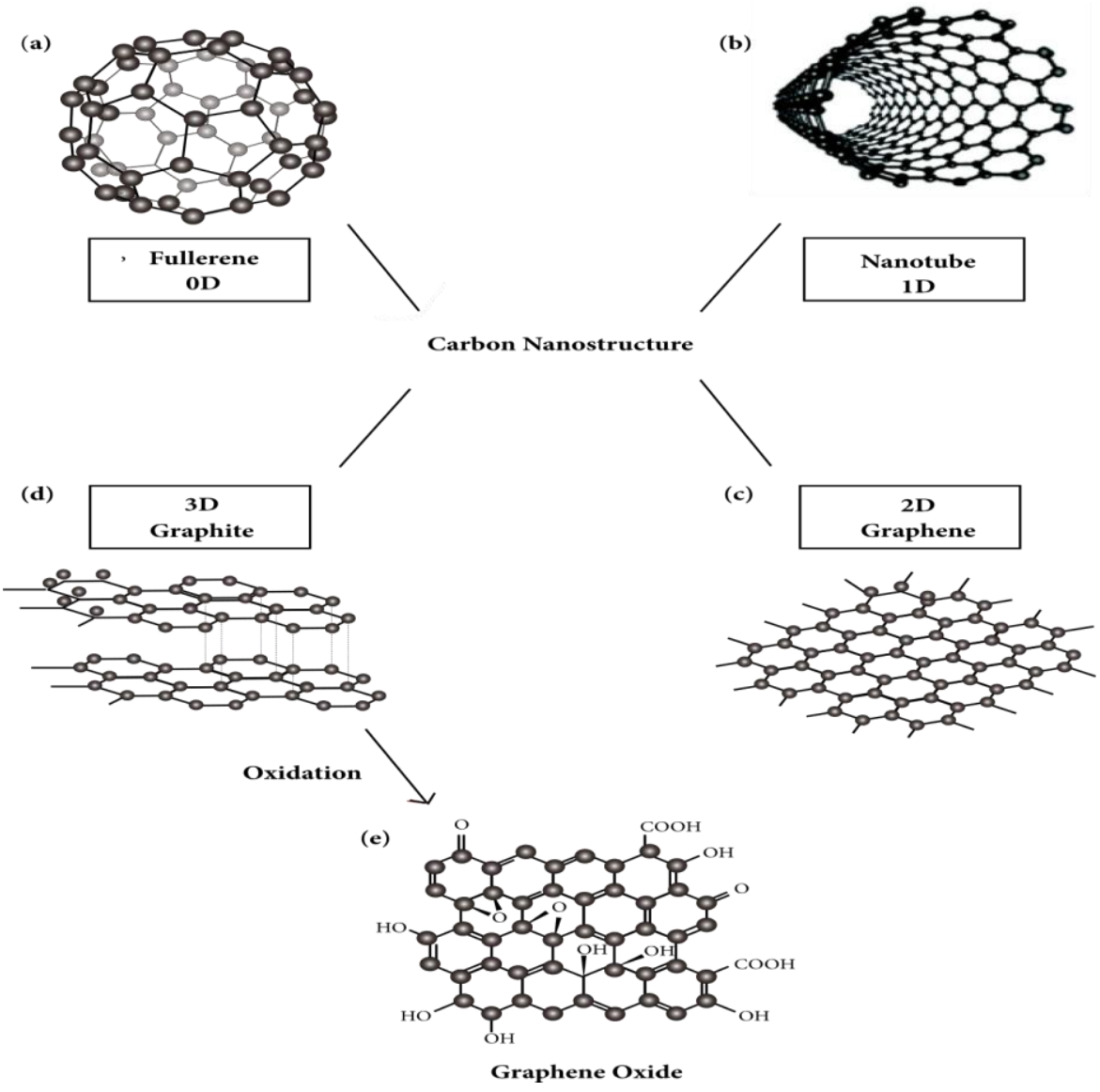

Figure 5: Allotropes of carbon nanostructures: (a) OD Fullerenes; (b) 1D Carbon Nanotubes; (c) 2D Graphene; (d) 3D Graphite. (e) Graphene Oxide is synthesized through graphite oxidation [39]

\subsection{Chitosan Nanomaterials}

Chitosan is an organic compound typically found in the exoskeletons of various shellfish [38]. As a nanomaterial, chitosan exhibits many beneficial properties that can be used in dentistry. One of many reasons why chitosan nanoparticle applications are being researched in dentistry is due to the experimental demonstrated effect of induced bone growth in the human body and oral cavity. When titanium implants are coated with chitosan nanoparticles in adjunct with bone growth protein BPM-2, ectopic bone growth was observed in mice [37]. Additionally, acceleration of bone regeneration was observed in mice when chitosan nanomaterials were infused with additional protein growth factors. Within regenerative dentistry, use of chitosan nanomaterials may offer alternatives to stopgap procedures like dental fillings.

Chitosan nanoparticles also observe antibacterial properties. Antibacterial properties of chitosan nanomaterials are due to its chemical and polyatomic structure, as can be seen in Figure 6 [38].

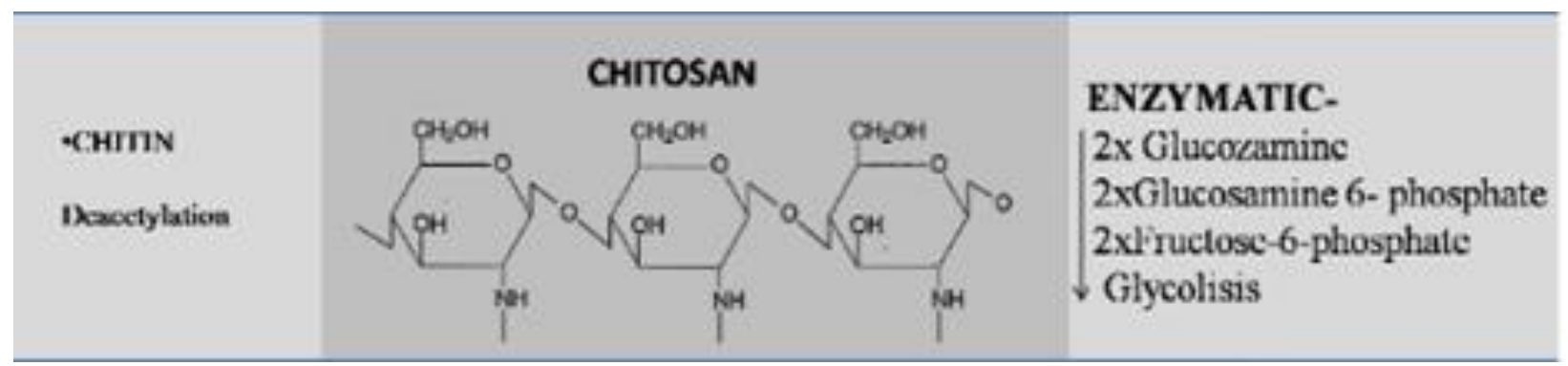

Figure 6: Chemical Composition of Chitosan [38] 
Researchers are pairing chitosan nanoparticles with various zinc-oxide-eugenol, calcium silicate and epoxy resin sealers, demonstrating improved antimicrobial properties of composite materials as a result. It is important for sealers to exhibit antimicrobial properties, as sealers are typically used for root canal procedures where there is direct exposure to nerve tissue. The exact mechanism for inducing antimicrobial properties in chitosan nanomaterials has yet to be determined. There is speculation as to whether antimicrobial properties of chitosan nanomaterials are a result of direct contact via material-bacterial interaction or via area effect [38].

A study conducted by Nair et al. on chitosan nanoparticles (CS-NPs) and zinc oxide nanoparticles (ZnO-NPs) against two strains of Enterococcus faecalis was used to show antibiofilm efficacy [40]. E. faecalis ATCC 29212 and OGIRF strains were each tested in five different environments and their average optimal densities were then compared after a 24-hour period [40]. After the 24-hour period, the two strains of E. faecalis - ATCC 29212 and OGIRF, created a biofilm and their biomasses were able to be analyzed using microtiter plate assay with the use of crystal violet [40]. The root canal sealer used in this experiment was Apexit Plus. Group 1 represents Apexit Plus with ZnO-NPs, group 2 is Apexit Plus with CS-NPs, group 3 was Apexit Plus by itself, group 4 was a positive control group with no sealers or nanoparticles, and group 5 was a negative, sterile control group.

Group 1 was found to have the greatest reduction in average optical density in both strains of $E$. faecalis when compared to the positive control group. However, also group 2, the environment with Apexit Plus with CS-NPs, demonstrated improved antibacterial activity compared to that of group 4, the positive control environment [40].

A second study of confocal laser scanning microscopy (CLSM) was also conducted with 1 week old biofilm to observe the antibacterial effectiveness [40]. The two strains of E. faecalis in their same four individual groups, as in the first experiment, were analyzed by their thicknesses.

Through investigation of ATCC 29212 the data showed a significant reduction in thickness of group 1 compared to the other groups. Also, once again group 2, the environment with Apexit Plus with CS-NPs, demonstrated improved antibacterial activity compared to that of group 4, the positive control environment for the ATCC 29212 strain [40]. However, all groups of OGIRF strain had little to no change in their biofilm thickness after 1 week [40].

A third study of the biofilms was conducted using $200 \mu \mathrm{L}$ of solution from group 1, group 2 and group 3 [40]. They were placed in glass wells and were left for 24 hours at $37^{\circ} \mathrm{C}$. After the 24-hour period, they were removed from the wells dyed with a propidium iodide stain (which is used to differentiate between living and dead bacterial cells by the colours green and red respectively) and a biofilm was placed on top [40]. These were left to rest for 10 minutes in the dark.

It was seen that group 3 with E. faecalis ATCC29212 had extreme amounts of living bacterial cells compared to dead bacterial cells. Whereas groups 1 and 2 effectively diminished the presence of the two strains at a much higher rate. This is because the thickness notably decreased. group 1, with $E$. faecalis OGIRF, killed many of the bacterial cells. However, the thicknesses in group 1 with $E$. faecalis OGIRF and group 2 with $E$. faecalis OGIRF had not been compromised, meaning that the thickness of E. faecalis OG1RF were not influenced by ZnO-NPs or CS-NPs [40].

As mentioned previously, the biocompatibility of products looking to be employed in the dental profession are of prime importance in order to protect patients from potential cytotoxic effects. In a study conducted by Elgendy et al. chitosan nanoparticles were compared to propolis, a resinous substance that comes from beehives, as well as non-nanosized chitosan nanoparticles [41]. Propolis, in recent years, has gained interest in its applicability in restorative dentistry due to its improved antibacterial activity [42]. Elgendy et al. proved however through their study, in which dental pulp stem cells were exposed to chitosan nanoparticles, propolis nanoparticles and standard chitosan particles, that the chitosan nanoparticles exhibited the least cytotoxic effects and resulted in the least characteristic cell changes [41].

Despite promising bone regenerative and antibacterial properties chitosan nanomaterials are not without their drawbacks. Chitosan nanomaterials exhibit weak processing and mechanical properties, as well as complete insolubility in many common organic solvents [38]. Researchers are attempting to mitigate these drawbacks by infusing chitosan nanomaterials with various other organic and inorganic nanomaterials.

\subsection{Zirconia Nanomaterials}

Zirconium Dioxide $\left(\mathrm{ZrO}_{2}\right)$ - Zirconia - observes a crystalline structure, a melting point of $2,715{ }^{\circ} \mathrm{C}$, and resembles the colour of healthy teeth [43]. Due to these characteristics, Zirconia is a sought-after ceramic in the dental industry [44]. Its crystalline structure increases its strength, durability, weatherability, and erosion resistance. At high temperatures, stable Zirconia permits the free movement of oxygen ions throughout its crystalline structure, increasing electrical conductivity making it a very useful electro-ceramic material [45]. As a chemical oxide, zirconia is insoluble in water decreasing bacterial adhesion [46,47]. Using advanced dental technology, three-unit zirconia ceramics show promising results regarding Fixed Partial Dentures (FPD) by computer aided design/computer aided manufacturing (CAD/CAM) [48]. In vitro experiments determined that Zirconia fulfills many of the characteristics considered necessary for dental fillings and dentures [48]. Biomedical implementations of zirconium have been increasing over the years and continue to be used throughout the field [49]. 


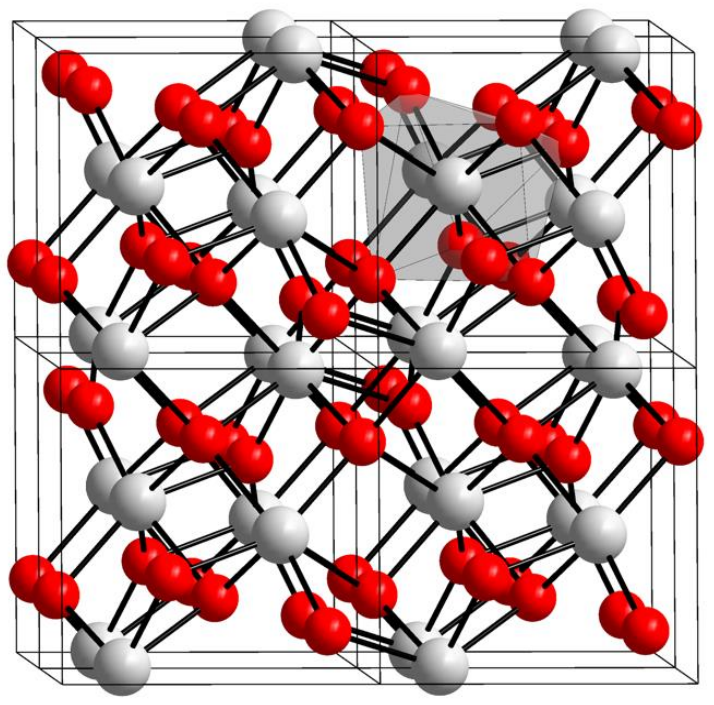

Figure 7: Anatomical crystalline arrangement of Zirconia (ZrO2) [50]

\subsection{Gold Nanoparticles}

Gold nanoparticles are gaining relevance in the field of dental fillings, due to their potential use as inert carriers for medical purposes and since they are harmless, precise, and rigid [51,52]. Elemental gold or its ions, can be absorbed in the gastrointestinal tract. Data regarding the oral toxicity of elemental gold is limited [51]. There were tests done on rats using a single dose of $2000 \mathrm{mg}$ nanoparticles $/ \mathrm{kg}$ of body weight. The lack of information regarding multiple doses has raised concerns [51]. Skin rashes have been documented in humans following the ingestion of liquors containing gold. In vitro studies show that gold nanoparticles in mammals induce DNA damage [51]. There should be more time and consideration taken to understand the effects of gold nanoparticles, for how frequent they are used in dental fillings.

\section{PREVENTATIVE MEASURES AGAINST PRIMARY OR SECONDARY CARIES PRIOR TO DENTAL FILLINGS}

As mentioned before, the most common problem seen by dental professionals are those of dental caries, which cause dental cavities. However, another major cause for dental appointments are the failures of the presently used dental fillings, whether it be due to mechanical failure or as a result of secondary caries, as previously mentioned. Advancements in the Biomedical Engineering research of nanomaterial based dental fillings is a reactionary solution to the problem. However, there are also potential proactive solutions to dental caries. In other words, there are Biomedical applications of nanomaterials, which can prevent the problem of dental caries in the first place. For example, there are developments for a toothbrush with nanomaterials. In between the bristles of the toothbrush, colloidal gold or silver will be placed which can lead to an improvement in dental health and thus a reduction in dental caries [53]. Colloidal silver or gold is simply their respective nanoparticles submerged in a solvent [54]. Negative phosphate molecules gravitate towards the positively charged silver and gold, which then aids in the destruction of biofilms and/or plaque [53].

\subsection{Starch Nanoparticles and Early Diagnosis of Caries}

Nanomaterials are now being recognized as a method to limit the need for dental professionals from needing to carry out full dental filling procedures. Dental professionals run the risk of overlooking early signs of caries through the use of visual and tactile exam tools [55]. Currently, X-Ray imaging is a popular method for caries detection, however this requires the caries to be significantly developed, otherwise the X-Rays will not detect them [55]. Regardless, when operating with these procedures, the solution is to resort to the "drill and fill" method, which is not ideal due to its invasive nature [55]. At the onset of caries development, very small holes begin to develop in the enamel (outer layer) of the tooth. As a result, Greenmark, a healthcare start-up, received approval from the Food and Drug Administration agency in March, 2021 for a product called Lumicare ${ }^{T M}$ Caries Detection Rinse, which utilizes the benefits of starch nanoparticles [55]. Molecules within the starch nanoparticles glow in the presence of a luminated blue curing light, as seen in Figure 8. 


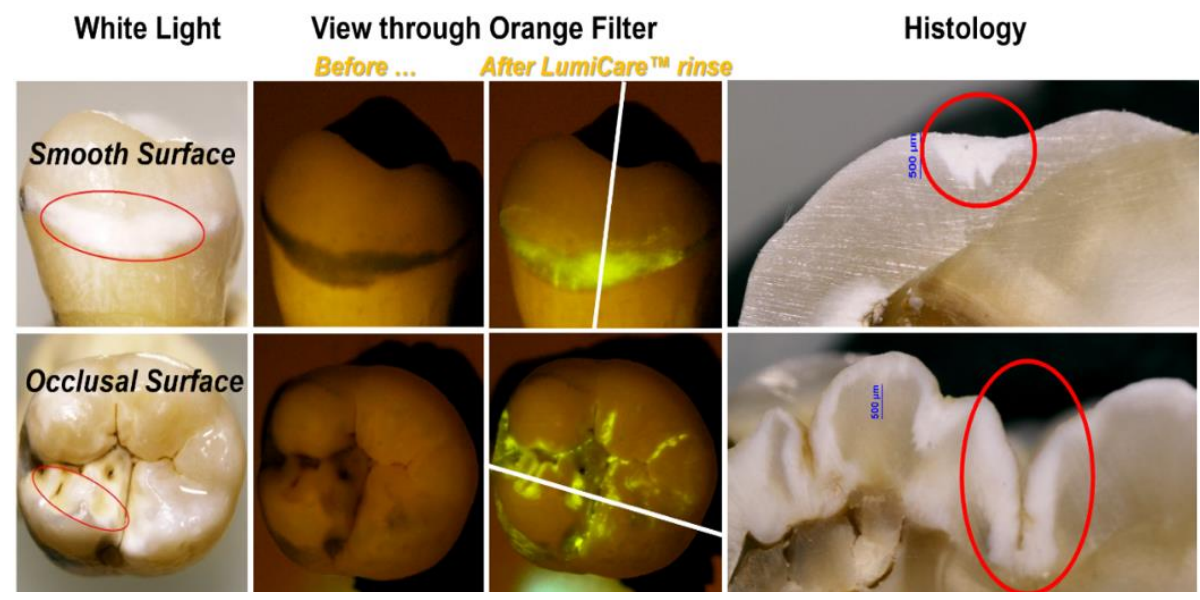

Figure 8: Reproduced Figure with Permission from Greenmark Biomedical Inc Illustrating the Starch Nanoparticles' Ability to Fluoresce [55]

As summarized in Figure 9, a patient will start by rinsing their mouth out with the Greenmark Rinse, and as they are rinsing, the miniscule starch nanoparticles are able to enter through the tiny porosities in the enamel and then get trapped around the early caries [55]. The patient then rinses their mouth, essentially ridding the oral cavity of all substances other than the starch nanoparticles in the porosities [55]. When the dental professional then shines the blue curing light, the starch nanoparticles then fluoresce, revealing the locations of the early caries, which can then be treated non-invasively [55].

Furthermore, Greenmark is also developing a product called CrystLCare ${ }^{T M}$ Restorative Gel, which contains starch nanoparticles bonded with calcium and phosphate, two of the most important minerals that are reduced in concentration during the onset of caries [55]. As mentioned previously, the starch nanoparticles can penetrate through the openings in the enamel and then attach to the developing caries [55]. Once all of this takes place, the starch particles disintegrate, thus allowing the now detached calcium and phosphate to re-mineralize the decayed tooth [55]. Part of why the use of starch particles is so beneficial is that there is no safety concern due to their biocompatibility and degradability in the oral cavity [55].

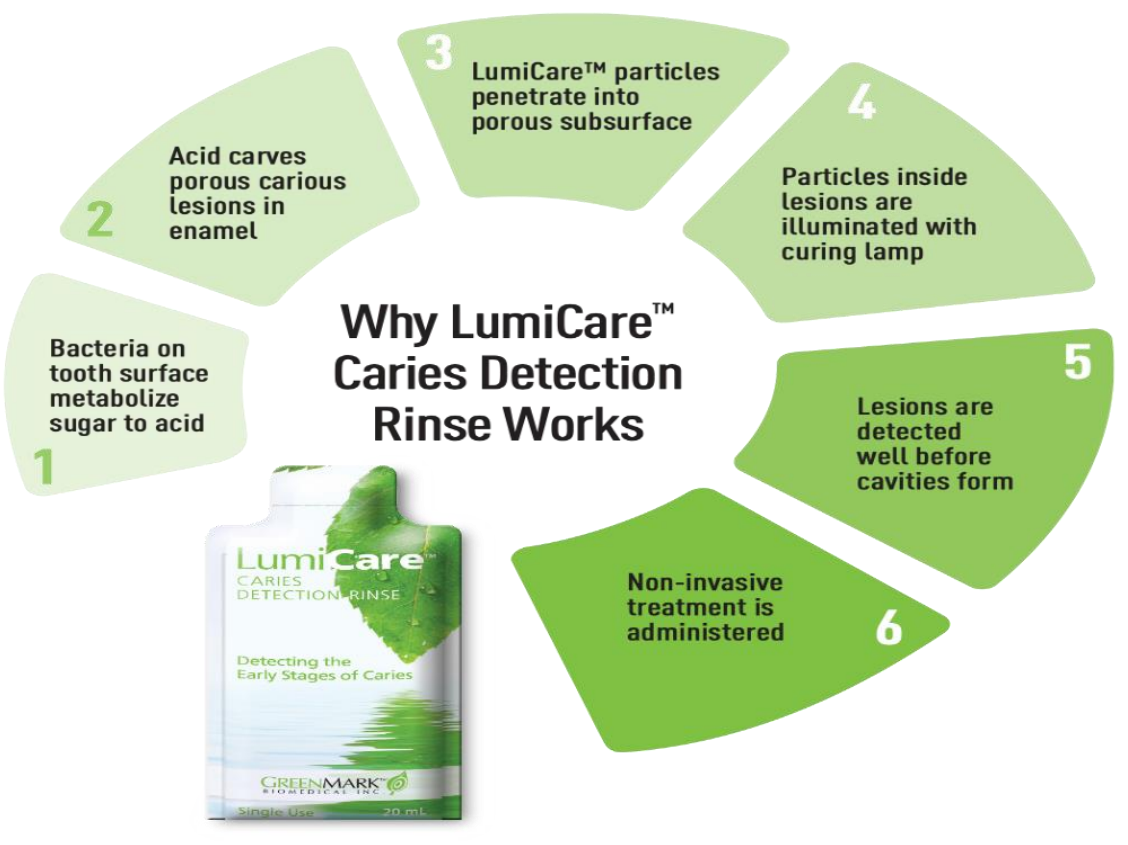

Figure 9: Privately Redistributed Figure from Greenmark Biomedical Inc Explaining the Step-by-Step Procedure of How the Lumicare ${ }^{T M}$ Caries Detection Rinse Works 


\subsection{Glycine Guided Nanoparticles}

Minimal Invasive Dentistry (MID) is a dental practice where dentists work to preserve original dental tissue. This can include performing early but small cavity fillings, in order to prevent significant future damage to the tooth. Dental decay is a result of the hydroxyapatite (HAP) mineral ions loss on the enamel. This is known as demineralization [56]. Under MID, the primary method used to treat tooth decay is fluoride application. Fluoride treatments provide remineralization to the demineralized tooth. There are however drawbacks to fluoride treatment, as mineral ions in fluoride are difficult to maneuver [56]. Remineralization treatments should have the same micro-architecture and organization as the original biological mineral crystals. Research demonstrated that HAP@ACP core-shell nanoparticles can be organized just like the original biological mineral crystals. Experiments determined that after 48 hours of HAP@ACP, nanoparticles with Gly formed mineral-like enamel crystals [56].

\subsection{Nanomaterial Toothpastes}

A Japanese study was conducted to investigate the possibility of nanomaterial infused toothpaste. In this study, nanohydroxyapatite particles (NHAP) were incorporated into a toothpaste solution [57]. It was observed that the nanoparticles that were infused in the toothpaste significantly increased tooth enamel microhardness relative to toothpaste not infused with nanoparticle solution. Experimental trials demonstrated a $56 \%$ reduction in cavity formation of nanomaterial infused vs. non-nanomaterial infused toothpastes. [57].

Additional experiments were conducted to test the influences on tooth hardness and the remineralization effect using 3\% nanosized sodium tri-metaphosphate infused toothpaste [58]. The remineralization effect pertains to the prevention of a caries progressing into a cavity, which is a later stage [59]. It was found that the addition of nanosized sodium tri-metaphosphate had significant influences on both tooth hardness and remineralization. Enamel hardness increased by $20 \%$ while the remineralization effect of the enamel increased by $66 \%$ [58]. There has also been additional research into the use of nanoparticles in mouthwashes, which found that the addition of nano-calcium fluoride reduces the potential for caries [57].

\subsection{Silver and Calcium Phosphate Nanoparticle Dental Adhesives}

A study was conducted to test the effectiveness of adding silver nanoparticles (NAg) and amorphous calcium phosphate nanoparticles (NACP) to an adhesive in breaking down biofilms, remineralization of both the dentin and enamel of the tooth, and the bond strength of the dentin [60]. Low percentages of NAg were added to the adhesive, while larger percentages of the mass of the adhesive was occupied by the NACP [58]. It was found through this experiment that the additional nanoparticles had a significant positive effect on the antibacterial properties of the adhesive and the remineralization of the dentin and enamel. Furthermore, while the dentin bond strength was of prime concern, it was found to not be affected by the additional nanoparticles [60].

\section{CONCLUSIONS}

There has been a great deal of research done regarding dental filling nanomaterials and nanoparticles. Not one material has proven to have all the beneficial qualities/characteristics desired for the filling. However, there are materials that have stood out as being a better option. As more research is being piloted, more knowledge is available to professionals in the industry, allowing them to give patients the best dental care possible.

1. Promising current research regarding dental filling nanomaterial applications involve nanocomposites, dental cement, glycine guided nanoparticles, nanomaterial resins, silica coated nanomaterials, silver coated and other metallic based nanoparticles.

2. Of the three most used nanomaterial dental fillers - carbon nanotubules, silver nanomaterials and silica nanomaterials - silica nanomaterials were observed to be the best current option due to its low cost, improved wear resistance, improved physical and mechanical properties, improved antibacterial properties and comparable toxicity levels under controlled concentrations.

3. The most important properties that were investigated with dental fillings nanomaterials are the resistance to wear, toxicity and the overall biocompatibility of the material. For the biocompatibility of dental filling nanomaterials, several reactive properties were analyzed, those being corrosion by $\mathrm{pH}$, temperature, protein, saliva, oral health conditions, and diet.

4. The current literature on the cytotoxic effects of various nanomaterials is conflicting, and thus more research should be conducted into the safety of introducing nanomaterials into the oral cavity.

5. Developmental strides are being made regarding future applications of graphene family nanomaterials (GFN), chitosan nanomaterials and gold nanoparticles for use in dental filling and dental filling processes.

6. Starch nanoparticles are currently being utilized to create new products that aid in detection of early caries, as well as treat early caries by recrystallizing of the decayed tooth.

7. Innovations regarding cavity prevention via nanoparticle use in toothpastes are being seen. With continued research, nanomaterials offer solutions to dental filling problems not previously available through traditional dental filling materials. 


\section{REFERNCES}

1. Dental health services in Canada. (n.d.). Retrieved from https://www.cdaadc.ca/stateoforalhealth/servicescanada/

2. American Dental Association (n.d.). Retrieved from https://www.ada.org/en/publications/ada-news/2017archive/december/hpi-report-shows-dental-spending-increased-again-in-2016

3. Endodontic Treatment Statistics. (n.d.). Retrieved from https://www.aae.org/specialty/about-aae/newsroom/endodontic-treatment-statistics/

4. Maserejian, N., Trachtenberg, F., Assmann, S., \& Barregard, L. (2008). Dental Amalgam Exposure and Urinary Mercury Levels in Children: The New England Children's Amalgam Trial. Environmental Health Perspectives, 116(2), 256-262.

5. Priyadarsini, S., Mukherjee, S., \& Mishra, M. (2018). Nanoparticles used in dentistry: A review. Journal of Oral Biology and Craniofacial Research, 8(1), 58-67. doi: 10.1016/j.jobcr.2017.12.004

6. Khurshid, Z., Zafar, M., Qasim, S., Shahab, S., Naseem, M., \& Abureqaiba, A. (2015). Advances in Nanotechnology for Restorative Dentistry. Materials, 8(2), 717-731. doi: 10.3390/ma8020717

7. Netto, L. R. C., Borges, A. L. S., Guimarães, H. B., Almeida, E. R. N. D., Poskus, L. T., \& Silva, E. M. D. (2015). Marginal integrity of restorations produced with a model composite based on polyhedral oligomeric silsesquioxane (POSS). Journal of Applied Oral Science, 23(5), 450-458. doi: 10.1590/1678-775720150041

8. Manivasagam, Geetha \& Dhinasekaran, Durgalakshmi \& Rajamanickam, Asokamani. (2010). Biomedical Implants: Corrosion and its Prevention -A Review. Recent Patents on Corrosion Science. 2. 40-54. 10.2174/1877610801002010040.

9. Hasan M. 2020. Chapter 9: Toxicity and Corrosion. Slide 4. Department of Mechanical and Industrial Engineering. Ryerson University, Toronto (Ontario).

10. Royal Society of Chemistry. $\quad$ (n.d). $\quad$ Retrieved from https://www.rsc.org/cpd/teachers/content/filerepository/frg/pdf/Nanoparticles.pdf

11. Adabi, M., Naghibzadeh, M., Adabi, M., Zarrinfard, M. A., Esnaashari, S. S., Seifalian, A. M., ... Ghanbari, H. (2016). Biocompatibility and nanostructured materials: applications in nanomedicine. Artificial Cells, Nanomedicine, and Biotechnology, 45(4), 833-842. doi: 10.1080/21691401.2016.1178134

12. Salim, F. M. (2019). Tribological and Mechanical Characteristics of Dental Fillings Nanocomposites. Energy Procedia, 157, 512-521. doi: 10.1016/j.egypro.2018.11.215

13. Chen, S., Yang, J., Jia, Y., Lu, B., \& Ren, L. (2019). TiO2 and PEEK Reinforced 3D Printing PMMA Composite Resin for Dental Denture Base Applications. Nanomaterials, 9(7), 1049. doi:10.3390/nano9071049

14. Kamonwanon, P., Yodmongkol, S., Chantarachindawong, R., Thaweeboon, S., Thaweeboon, B., \& Srikhirin, T. (2015). Wear resistance of a modified polymethyl methacrylate artificial tooth compared to five commercially available artificial tooth materials. The Journal of Prosthetic Dentistry, 114(2), 286-292. doi:10.1016/j.prosdent.2015.01.013

15. Christos Angeletakis. Minh-Dang Son Nguyen. (2001). US6593395B2 - Dental composition containing discrete nanoparticles. Retrieved from https://patents.google.com/patent/US6593395B2/en

16. Cesero, L. D., Oliveira, E. M., Junior, L. H., Papaléo, R. M., \& Mota, E. G. (2017). The addition of silica nanoparticles on the mechanical properties of dental stone. The Journal of Prosthetic Dentistry, 118(4), 535539. doi:10.1016/j.prosdent.2017.01.001

17. Song, J., Kong, H., \& Jang, J. (2009). Enhanced antibacterial performance of cationic polymer modified silica nanoparticles. Chemical Communications, (36), 5418. doi:10.1039/b908060k

18. Wang, H., Zhu, M., Li, Y., Zhang, Q., \& Wang, H. (2011). Mechanical properties of dental resin composites by co-filling diatomite and nanosized silica particles. Materials Science and Engineering: C, 31(3), 600-605. doi:10.1016/j.msec.2010.11.023

19. Nevarez-Rasconb, A. Orrantia-Borundaa, E. González-Hernándeza, J. Flores-Gallardoa, S. Hurtado-Macíasa, A. (1 December 2014). Mechanical characterization of optical glass fiber coated with a thin film of silver nanoparticles by nanoindentation. Volume 136, Pages 63-66.

20. Jeong-Ho Lee. Palanivel Velmurugan. Jung-Hee Park. Kui-Jae Lee. Jong-Sik Jin. Yool-Jin Park. Keuk-Soo Bang. Byung-Taek Oh. (June 2016). In vitro fabrication of dental filling nanopowder by green route and its antibacterial activity against dental pathogens. Volume 159, Pages 229-236

21. Mohammad Ali Saghiri. Mehrdad Lotfi. Houtan Aghili. (2011). Dental cement composition. Retrieved from https://patents.google.com/patent/US8668770B2/en

22. Drobny, J. G. (2014). Thermoplastic Elastomers Based on Recycled Rubber and Plastics. Handbook of Thermoplastic Elastomers, 297-299. doi:10.1016/b978-0-323-22136-8.00014-4

23. Prakash, D. R., Gopikrishna, D. V., \& Kandaswamy, D. D. (n.d.). GUTTA-PERCHA - AN UNTOLD STORY. Retrieved from http://medind.nic.in/eaa/t05/i2/eaat05i2p32.pdf

24. Authors: John Sawyer Professor Dr. John Sawyer is a professor of agronomy and extension specialist in soil fertility and nutrient management at lowa State University. Gypsum: an Old Product with a New Use. crops.extension.iastate.edu/encyclopedia/gypsum-old-product-new-use.

25. Osterwalder, N., Loher, S., Grass, R. N., Brunner, T. J., Limbach, L. K., Halim, S. C., \& Stark, W. J. (2006). Preparation of nano-gypsum from anhydrite nanoparticles: Strongly increased Vickers hardness and formation 
of calcium sulfate nano-needles. Journal of Nanoparticle Research, 9(2), 275-281. doi:10.1007/s11051-006-91497

26. Makvandi, P., Gu, J. T., Zare, E. N., Ashtari, K., Moeini, A., Tay, F. R., \& Niu, L. (2019). Polymeric and Nanoscopical antimicrobial fillers in dentistry. SSRN Electronic Journal. doi:10.2139/ssrn.3407082

27. Nanodiamond-Gutta percha COMPOSITE BIOMATERIALS for root Canal therapy - full text view. (n.d.). Retrieved April 16, 2021, from https://clinicaltrials.gov/ct2/show/NCT03376984

28. Ferracane J. L. (2017). Models of Caries Formation around Dental Composite Restorations. Journal of dental research, 96(4), 364-371. https://doi.org/10.1177/0022034516683395

29. Bhattacharya, M., \& Seong, W. (2019). Carbon nanotube-based materials-preparation, biocompatibility, and applications in dentistry. Nanobiomaterials in Clinical Dentistry, 41-76. doi:10.1016/b978-0-12-8158869.00003-6

30. Kasraei, S., Sami, L., Hendi, S., AliKhani, M., Rezaei-Soufi, L., \& Khamverdi, Z. (2014). Antibacterial properties of composite resins incorporating silver and zinc oxide nanoparticles onstreptococcus mutansandlactobacillus. Restorative Dentistry \& Endodontics, 39(2), 109. doi:10.5395/rde.2014.39.2.109

31. Friedman, J. Y. (2011). The Role of Streptococcus Mutans in the Formation of Dental Caries: An Ecological Perspective. The Science Journal of the Lander College of Arts and Sciences, 5(1). Retrieved from https://touroscholar.touro.edu/sjlcas/vol5/iss1/5

32. Ahirwar SS, Gupta MK and Snehi SK: Dental caries and lactobacillus: role and ecology in the oral cavity. Int J Pharm Sci \& Res 2019; 10(11): 4818-29. doi: 10.13040/IJPSR.0975-8232.10(11).4818-29.

33. Brian H. (2020). Finding the Silver Lining - Zoom Presentation. Kerr Restoratives.

34. Bahadar, H., Maqbool, F., Niaz, K., \& Abdollahi, M. (2016). Toxicity of Nanoparticles and an Overview of Current Experimental Models. Iranian biomedical journal, 20(1), 1-11. https://doi.org/10.7508/ibj.2016.01.001

35. Chakraborty RK, Sharma S. Bronchoalveolar Cancer. [Updated 2021 Mar 1]. In: StatPearls [Internet]. Treasure Island (FL): StatPearls Publishing; 2021 Jan-. Available from: https://www.ncbi.nlm.nih.gov/books/NBK513281/

36. Zhang, J. F., Wu, R., Fan, Y., Liao, S., Wang, Y., Wen, Z. T., \& Xu, X. (2014). Antibacterial dental composites with chlorhexidine and mesoporous silica. Journal of dental research, 93(12), $1283-1289$. https://doi.org/10.1177/0022034514555143

37. Stewart, C. A., Hong, J. H., Hatton, B. D., \& Finer, Y. (2018). Responsive antimicrobial dental adhesive based on drug-silica co-assembled particles. Acta Biomaterialia, 76, 283-294. doi:10.1016/j.actbio.2018.06.032

38. Virlan, M., Miricescu, D., Radulescu, R., Sabliov, C., Totan, A., Calenic, B., \& Greabu, M. (2016). Organic nanomaterials and their applications in the treatment of ORAL DISEASES. Molecules, 21(2), 207. doi:10.3390/molecules21020207

39. Ge, Z., Yang, L., Xiao, F., Wu, Y., Yu, T., Chen, J., Zhang, Y. (2018). Graphene Family Nanomaterials: Properties and Potential Applications in Dentistry. International Journal of Biomaterials, 2018, 1-12. doi: $10.1155 / 2018 / 1539678$

40. Nair, N., James, B., Devadathan, A., Johny, M. K., Mathew, J., \& Jacob, J. (2018). Comparative Evaluation of Antibiofilm Efficacy of Chitosan Nanoparticle- and Zinc Oxide Nanoparticle-Incorporated Calcium HydroxideBased Sealer: An In vitro Study. Contemporary clinical dentistry, 9(3), 434-439.

41. Elgendy AA, Fayad DM. Cell viability and apoptotic changes of dental pulp stem cells treated with propolis, chitosan, and their nano counterparts. Tanta Dent J 2017;14;198-207

42. Abbasi, A. J., Mohammadi, F., Bayat, M., Gema, S. M., Ghadirian, H., Seifi, H., Bayat, H., \& Bahrami, N. (2018). Applications of Propolis in Dentistry: A Review. Ethiopian journal of health sciences, 28(4), $505-512$. https://doi.org/10.4314/ejhs.v28i4.16

43. Piconi C., Maccauro G. Zirconia as a ceramic biomaterial. Biomaterials. 1999;20:1-25

44. Nielsen, R. H., \& Wilfing, G. (2010). Zirconium and Zirconium Compounds. doi:doi:10.1002/14356007.a28_543.pub

45. George, M. (2020). National Minerals Information Center. From https://www.usgs.gov/centers/nmic/zirconium-and-hafnium-statistics-and-information

46. Zarone F., Russo S., Sorrentino R. From porcelain-fused-to-metal to zirconia: clinical and experimental considerations. Dent Mater J. 2011;27:83-96.

47. Lughi V., Sergo V. Low temperature degradation-aging-of zirconia: a critical review of the relevant aspects in dentistry. Dent Mater. 2010;26:807-820.

48. Vigolo, P., \& Fonzi, F. (2008). An in vitro evaluation of fit of Zirconium-Oxide-Based ceramic Four-Unit fixed partial dentures, generated with three different CAD/CAM systems, before and after porcelain firing cycles and after glaze cycles. Journal of Prosthodontics, 17(8), 621-626. doi:10.1111/j.1532-849X.2008.00366.x

49. Chellan, P., \& Sadler, P. (2015). The elements of life and medicines. Philosophical Transactions: Mathematical, Physical and Engineering Sciences, 373(2037), 1-56. From http://www.jstor.org/stable/24506181

$\begin{array}{llll}\text { 50. "Zirconium } \quad \text { Wioxide," } & \text { 23-Jun-2020. }\end{array}$ https://en.wikipedia.org/wiki/Zirconium_dioxide. [Accessed: 07-Aug-2020].

51. Hadrup, N., Sharma, A. K., Poulsen, M., \& Nielsen, E. (2015). Toxicological risk assessment of elemental gold following oral exposure to sheets and nanoparticles - a review. Regulatory Toxicology and Pharmacology, 72(2), 216 221. doi:10.1016/j.yrtph.2015.04.017 
52. Carr A.B., Brunski J.B., Hurley E. Effects of fabrication, finishing, and polishing procedures on preload in prostheses using conventional 'gold' and plastic cylinders. Int J Oral Maxillofac Implants. 1996:11.

53. C. Raval, K. Vyas, U. Gandhi, B. Patel, P. PatelNanotechnology in dentistry: a review J. Adv. Med. Dental Sci. Res., 4 (3) (2016), p. 51

54. NanoComposix. (n.d.). Gold Colloid. Retrieved August 04, 2020, from https://nanocomposix.com/pages/goldcolloid

55. Shuman, L. (2020, May). Changing the way we see caries - literally. Oralhealth, 66-66.

56. Wang, H., Xiao, Z., Yang, J., Lu, D., Kishen, A., Li, Y., Zhang, X. (2017). Oriented and ordered biomimetic remineralization of the surface of demineralized dental enamel using HAP@ACP nanoparticles guided by glycine. Scientific Reports, 7(1), 40701. doi:10.1038/srep40701

57. AlKahtani, R. N. (2018). The implications and applications of nanotechnology in dentistry: A review. The Saudi Dental Journal, 30(2), 107-116. doi:10.1016/j.sdentj.2018.01.002

58. M. Danelon, J.P. Pessan, F.N.S. Neto, E.R. de Camargo, A.C.B. Delbem Effect of toothpaste with nano-sized trimetaphosphate on dental caries: in situ study J. Dentistry, 43 (7) (2015), pp. 806-813

59. Alhamed, M., Almalki, F., Alselami, A., Alotaibi, T., \& Elkwatehy, W. (2020). Effect of different remineralizing agents on the initial carious lesions - a comparative study. The Saudi Dental Journal, 32(8), 390-395. doi:10.1016/j.sdentj.2019.11.001

60. Melo, M. A., Cheng, L., Zhang, K., Weir, M. D., Rodrigues, L. K., \& Xu, H. H. (2013). Novel dental adhesives containing nanoparticles of silver and amorphous calcium phosphate. Dental Materials, 29(2), 199-210. doi:10.1016/j.dental.2012.10.005 